\title{
Genetic Diversity and Tissue and Host Specificity of Grapevine vein clearing virus
}

\author{
Qiang Guo, Shae Honesty, Mei Long Xu, Yu Zhang, James Schoelz, and Wenping Qiu
}

All authors: Center for Grapevine Biotechnology, William H. Darr School of Agriculture, Missouri State University, Mountain Grove 65711; and fourth and fifth authors: Division of Plant Sciences, University of Missouri, Columbia 65211.

Current address of M. L. Xu: The State Key Laboratory of Seedling Bioengineering, Ningxia Forestry Institute, Yinchuan, Ningxia, P.R. China 750004.

Accepted for publication 19 November 2013.

\begin{abstract}
Guo, Q., Honesty, S., Xu, M. L., Zhang, Y., Schoelz, J., and Qui, W. 2014. Genetic diversity and tissue and host specificity of Grapevine vein clearing virus. Phytopathology 104:539-547.

Grapevine vein clearing virus (GVCV) is a new badnavirus in the family Caulimoviridae that is closely associated with an emerging veinclearing and vine decline disease in the Midwest region of the United States. It has a circular, double-stranded DNA genome of 7,753 bp that is predicted to encode three open reading frames (ORFs) on the plus-strand DNA. The largest ORF encodes a polyprotein that contains domains for a reverse transcriptase (RT), an RNase $\mathrm{H}$, and a DNA-binding zinc-finger protein (ZF). In this study, two genomic regions, a 570-bp region of the RT domain and a 540-bp region of the ZF domain were used for an analysis of the genetic diversity of GVCV populations. In total, 39 recombinant plasmids were sequenced. These plasmids consisted of three individual clones from each of 13 isolates sampled from five grape

varieties in three states. The sequence variants of GVCV could not be phylogenetically grouped into clades according to geographical location and grape variety. Codons of RT or ZF regions are subject to purifying selection pressure. Quantitative polymerase chain reaction assays indicated that GVCV accumulates abundantly in the petioles and least in the root tip tissue. Upon grafting of GVCV-infected buds onto four major grape cultivars, GVCV was not detected in the grafted 'Chambourcin' vine but was present in the grafted 'Vidal Blanc', 'Cayuga White', and 'Traminette' vines, suggesting that Chambourcin is resistant to GVCV. Furthermore, seven nucleotides were changed in the sequenced RT and ZF regions of GVCV from a grafted Traminette vine and one in the sequenced regions of GVCV from grafted Cayuga White but no changes were found in the sequenced regions of GVCV in the grafted Vidal Blanc. The results provide a genetic snapshot of GVCV populations, which will yield knowledge important for monitoring GVCV epidemics and for preventing the loss of grape production that is associated with GVCV.
\end{abstract}

Grapevine is a host for $>60$ viruses that have RNA genomes $(17,18)$, as well as for two recently discovered DNA viruses, Grapevine vein clearing virus $(\mathrm{GVCV})$ and Grapevine Cabernet Franc-associated virus (16,34). Most grapevine viruses are present as genetically diverse populations in vineyards, which provides a selective advantage for them to adapt to grape varieties of diverse Vitis spp. and hybrids. For example, the Grapevine leafroll-associated viruses 1, 2, 3, and 7 (GLRaV-1, 2, 3, and 7) comprise a group of viruses associated with grapevine leafroll disease and exist as a population of sequence variants that can be clustered into evolutionarily distinct lineages $(2,4,13,30)$. Their genetic relatedness, however, is not clearly segregated into groups according to geographical location, suggesting that GLRaVs spread among grape-growing regions primarily through the distribution of previously infected grapevines $(2,13,30)$. Populations of Grapevine fanleaf virus (GFLV) contain sequence variants and quasispecies as a result of not only genetic mutations but also recombination within genetic variants of GFLV and between GFLV and other closely related viruses in the genus Nepovirus $(23,27)$. Grapevine rupestris stem pitting-associated virus (GRSPaV) also consists of mixtures of genetically diverse sequence variants $(3,22)$. Population structures of GRSPaV in scion varieties were different from those in rootstock varieties (19), indicating that rootstock varieties contribute additional factors in the diversification of the GRSPaV population structure $(3,19)$.

Corresponding author: W. Qiu; E-mail address: WenpingQiu@ missouristate.edu

http://dx.doi.org/10.1094/PHYTO-03-13-0075-R

(C) 2014 The American Phytopathological Society
GVCV is a provisional new species in the genus Badnavirus in the family Caulimoviridae, the first badnavirus discovered in grapevines (34). Its genome consists of a circular, doublestranded DNA molecule of $7,753 \mathrm{bp}$, with three open reading frames (ORFs) predicted on the plus strand of the genome. The longest, ORF3, encodes a polyprotein that contains domains for reverse transcriptase (RT), RNase $\mathrm{H}$, and a DNA-binding zincfinger (ZF) domain. GVCV is closely associated with the veinclearing and vine decline disease that poses an increasing threat to the sustainable production of grape varieties of Vitis vinifera and hybrid grape grown in the Midwest region of the United States $(25,34)$. Translucent vein-clearing is a distinct foliar symptom on the GVCV-infected vines. Symptomatic leaves are frequently succeeded by leaves expressing no or mild symptoms on the newly emerged branches of vines, although the degree and spectrum of symptoms varies slightly among varieties, individual vines, and vineyards in different geographical locations.

Plant virus species in the genus Badnavirus are determined by the percentage of sequence identity in their RT and RNase $\mathrm{H}$ regions (11). Furthermore, individual species exist as quasispecies in host plants such as cocoa $(21)$, sugarcane $(20)$, banana $(7,8,12)$, and gooseberry (33). For example, Cacao swollen shoot virus (CSSV), a mealybug-transmitted badnavirus found in major cocoa-growing areas of West Africa, currently comprises five isolates that are significantly different at the nucleotide sequence level (21). Geering et al. (6) identified four distinct Banana streak virus (BSV) isolates that differed in their genomic sequences by 20 to $30 \%$ in Australia (6). Similarly, BSV also is present as a highly variable population in Uganda (7). Furthermore, six new species of BSV were proposed after the complete genomes of 
BSV-like isolates were sequenced (12). The existence of diverse BSV sequence variants seriously complicates the delineation of BSV into species (12).

Grapevines are produced mainly through vegetative propagation by grafting scions onto rootstocks or by rooting woody or green cuttings. Vegetative propagation creates opportunities for various strains of a virus, or multiple viruses, to be introduced into a single vine $(1,26)$. Moreover, perennial growth of a grapevine increases genetic diversity of a virus, because a vine is exposed to multiple infections of different viral isolates transmitted by insect vectors during its lifetime. The viral population is under selection annually by the development of new tissues. As a result, an analysis of the nucleotide sequences of grapevine viruses in grape varieties that are grown at geographically separate regions can yield valuable knowledge about the genetic diversity of the virus, epidemics, and prevention of viral diseases.

To gain more knowledge of GVCV, we isolated GVCV sequences from susceptible grapevine varieties present in vineyards in Missouri, Illinois, and Indiana, and analyzed the population structure at the nucleotide sequence level. In addition, we assessed the copy number of GVCV in four types of tissues in a single plant and tested the susceptibility of four hybrid grape cultivars to GVCV. These studies provided clues about the potential routes of spread of GVCV, produced nucleotide sequences for designing primers for detection of GVCV, and identified tissues that can be sampled for the most reliable detection. Furthermore, these results contribute to a more in-depth understanding of the epidemiology, evolutionary biology, and host adaptation of GVCV. The finding that 'Chambourcin' grape is apparently resistant to GVCV lays the foundation for breeding GVCV-resistant grape and for genetic dissection of host resistance to GVCV.

\section{MATERIALS AND METHODS}

Grapevines and tissues. Young shoots of symptomatic vines were collected from 10- to 20-year-old commercial vineyards in 2009 and 2010 in Missouri, Illinois, and Indiana. The samples were stored on ice in a cooler and brought back to the laboratory for further processing. Leaves at the third or fourth position from the shoot tip were sampled from randomly selected shoots, weighed as $0.1 \mathrm{~g}$ frozen in liquid nitrogen, and stored at $-80^{\circ} \mathrm{C}$. A list of samples, cultivars, and their locations is presented in Table 1.

The 'Chardonel' vine 'LBC0903' from which GVCV was isolated and sequenced was selected as a source vine of GVCV. Hybrid grape Chambourcin, 'Vidal Blanc', 'Traminette', and 'Cayuga White' were propagated from hardwood cuttings in 2010 and were grown in potted soils in the greenhouse at the Missouri State Fruit Experiment Station, Mountain Grove. Hardwood chips were taken from the LBC0903 vine and grafted onto three vines of each cultivar (Chambourcin, Vidal Blanc, Traminette, and

TABLE 1. List of 13 Grapevine vein clearing virus isolates that were collected from five grape cultivars in Missouri, Illinois, and Indiana

\begin{tabular}{llll}
\hline Sample ID & \multicolumn{1}{c}{ Clones } & \multicolumn{1}{c}{ Variety } & \multicolumn{1}{c}{ Location } \\
\hline MOV221 & MOV221-1, 2, 3 & Cabernet Sauvignon & Augusta, MO \\
MOV223 & MOV223-1, 2, 3 & Cabernet Sauvignon & Augusta, MO \\
MOV227 & MOV227-1, 2, 3 & Cabernet Sauvignon & Augusta, MO \\
MOV230 & MOV230-1, 2, 3 & Chardonnay & Augusta, MO \\
MOV231 & MOV231-1, 2, 3 & Chardonnay & Augusta, MO \\
LBC0902 & LBC0902-1, 2, 3 & Chardonel & Boone, MO \\
LBC0903 & LBC0903-1, 2, 3 & Chardonel & Boone, MO \\
LBC1001 & LBC1001-1, 2, 3 & Chardonel & Boone, MO \\
ILV1001 & ILV1001-1, 2, 3 & Chardonel & Adams, IL \\
ILV1003 & ILV1003-1, 2, 3 & Chardonel & Pike, IL \\
ILV1004 & ILV1004-1, 2, 3 & Chardonel & Jackson, IL \\
IDV1002 & IDV1002-1, 2, 3 & Cabernet Franc & Knox, IN \\
IDV1004 & IDV1004-1, 2, 3 & Riesling & Knox, IN \\
\hline
\end{tabular}

Cayuga White) on 7 July 2011. In a second experiment, young shoots of LBC0903 were grafted onto the three-node green cuttings of five individual Chambourcin and Traminette vines on 16 May 2012. Only one of the LBC0903 shoot-grafted Chambourcin and Traminette green cuttings had a well-healed graft union and generated roots. These two plants were transferred to potted soils when roots were $\approx 2 \mathrm{~cm}$ long. The LBC0903 green scion healed well and started growing a young shoot, which was used to test for GVCV transmission from the scion to the recipient Chambourcin and Traminette vines. In a third experiment, LBC0903-infected hardwood buds were grafted onto three Chardonel and Chambourcin vines on 27 June 2012. Two grafted Chambourcin vines had a well-healed graft union and served as materials for further testing for their susceptibility to GVCV.

Three individual LBC0903 vines that had been grown in potted soils for 2 years were selected for the tissue-specificity study. Young leaves at the third position from the tip of the shoot and fully expanded leaves counted from the base of the shoot were collected. Petioles were collected from a fully expanded leaf. Root tips ( 2 to $3 \mathrm{~cm}$ long) were collected from secondary roots of each LBC0903 vine.

DNA extraction and polymerase chain reaction. Tissues were ground to a fine powder in liquid nitrogen and total DNA was extracted using a DNeasy Plant Mini Kit following the manufacturer's instructions (Qiagen Inc. Valencia, CA). At the final step, DNA was eluted twice, each time with $50 \mu$ of sterilized distilled $\mathrm{H}_{2} \mathrm{O}$. Total DNA was quantified by absorbance at 260/280 in a spectrophotometer, analyzed by electrophoresis on $1 \%$ (wt/vol) agarose gels in $1 \times$ Tris-acetate-EDTA buffer $(0.04 \mathrm{M}$ Tris, $0.018 \mathrm{M}$ glacial acetic acid, and $0.001 \mathrm{M}$ EDTA), and visualized by staining the gel with ethidium bromide (Fisher Biotech, Hanover Park, IL) at $0.5 \mathrm{ng} / \mathrm{ml}$.

The primer set GVCV3163F (5'-AGGGTAAAAACTGC GACGGCTA-3') and GVCV5880R (5'-GGACCTATGTCTGCT CTTGC-3') was used to amplify a 2,718-bp fragment $(3,163$ to 5,880 nucleotides [nt] of GVCV genome) for the restriction fragment length polymorphism (RFLP) analysis. Platinum Taq DNA Polymerase High Fidelity (Invitrogen, Grand Island, NY) was used for polymerase chain reaction (PCR) according to the manufacturer's instructions.

Routine detection of GVCV was performed by PCR with the primer set GVCV 5098F (5'-GTCAGACAACAAGAACAGGC GT-3') and GVCV5558R (5'-GCTATCTTTTGAGGTTCCAGG G-3'), which yields a 461-bp amplicon (5,098 to 5,558 nt of GVCV genome). To verify the presence of GVCV, a second PCR primer set was used (GVCV4142F, 5'-GTAAACCTCATGAC TCTCATG-3' and GVCV4387R, 5'-CTTCTCCTTCAGAAAT TGAGCAGAT-3'), which yields a 246-bp amplicon (4,142 to $4,387 \mathrm{nt}$ of GVCV genome). The primer set GVCV4142F and GVCV6721R (5'-ATCCKTCCATGCAWCCGTCAG-3') was used to generate a $2,580 \mathrm{bp}$ fragment $(4,142$ to $6,721 \mathrm{nt}$ of GVCV genome) for the genetic diversity study.

Analysis of GVCV amplicons by restriction enzyme digestion. The DNA fragment amplified by the primer set GVCV3163F and GVCV5880R was purified from a $1 \%$ agarose gel by the Qiagen MinElute Gel Extraction Kit for RFLP analysis. The DNA in an amount of $200 \mathrm{ng}$ was subjected to digestion with restriction enzymes PstI, EcoRV, and ApaI as recommended by the manufacturer (New England Biolabs, Ipswich, MA). Digestion was performed at $37^{\circ} \mathrm{C}$ for $1 \mathrm{~h}$. The digested PCR products were separated on a $1 \%$ agarose gel by electrophoresis, stained with ethidium bromide, and photographed.

Cloning of GVCV-specific fragments. The 2,580-bp PCR products $(4,142$ to $6,721 \mathrm{nt}$ of GVCV genome) were inserted into the $\mathrm{pCR} 8 / \mathrm{GW} / \mathrm{TOPO}$ vector following the manufacturer's instructions (Invitrogen), and recombinant plasmids were transformed into competent Escherichia coli. Colony PCR was performed to confirm positive colonies using Platinum Taq (Invitrogen) and the 
primer set GVCV5098F and GVCV5558R. Three colonies for each of the 13 isolates were randomly selected for sequence analysis (Table 1), and each colony was cultured in $5 \mathrm{ml}$ of Luria Broth medium containing spectinomycin $(100 \mu \mathrm{g} / \mathrm{ml})$. Recombinant plasmid DNA was extracted by using a Spin Miniprep Kit (Qiagen). Recombinant plasmid DNA was verified to contain the target fragment via PCR with universal primers within the vector region before it was sent out for sequencing.

Sequencing and sequence analysis. For each clone of the 13 isolates (Table 1), sequences of insert DNA from three individual colonies were determined at the Nevada Genomics Center, University of Nevada, Reno. Primers GW1 and GW2 from pCR8/ GW/TOPO TA Cloning Kit (Invitrogen) were used in sequencing for the RT and ZF region of each recombinant plasmid. The RT region of $570 \mathrm{bp}$ and $\mathrm{ZF}$ region of $540 \mathrm{bp}$ were aligned using CodonCode Aligner 4.1 (CodonCode Corporation, Centerville, MA). Multiple sequence alignments of the $39 \mathrm{RT}$ and ZF sequences were performed using the ClustalW program (29). The “.aln" document was converted into a MEGA5 document (28), and the best model having the lowest Bayesian Information Criterion score was found by "Find Best DNA/Protein Models". The unrooted phylogenetic trees, using the maximum-likelihood method, were generated following the best model with bootstrap replications at 1,000 .

Calculation of selection pressure and genetic parameters. The site-specific selection pressure for ZF and RT regions was estimated using Datamonkey software (http://www.datamonkey. org/) (15). Three methods were used for estimation of the ratio of nonsynonymous substitutions per nonsynonymous site $(\mathrm{d} N)$ to synonymous substitutions per synonymous site $(\mathrm{d} S)$ : singlelikelihood ancestor counting, fixed-effects likelihood, and random-effects likelihood. Based on normalized $\mathrm{d} N-\mathrm{d} S$ values for $\mathrm{RT}$ and $\mathrm{ZF}$ regions, we considered that the virus is under negative or purifying selection pressure if $\mathrm{d} N-\mathrm{d} S<1$, positive or diversifying selection pressure if $\mathrm{d} N-\mathrm{d} S>1$, and neutral selection pressure if $\mathrm{d} N-\mathrm{d} S=1$.

The three clones for each isolate were considered as one group. The overall mean of intra- and interisolate diversity was calculated by performing "compute mean diversity within subpopulations" and "compute mean inter-population diversity" in a MEGA5 software with a best-fit model. The genetic differentiation of ZF and RT regions resulting from locations and grape varieties was estimated by DnaSP software 5.10.01 (http://www. dnasp.com-about.com). Wright's statistic of $\mathrm{F}_{\mathrm{ST}}$ of 0 to 1.00 was used to indicate the proportion of genetic variation between subpopulations in the total genetic variation (32). An $\mathrm{F}_{\mathrm{ST}}>0.05$ suggests that there is differentiation among subpopulations. Hudson's statistic of $\mathrm{K}_{\mathrm{ST}} *$ and $\mathrm{S}_{\mathrm{nn}}$ was used to identify the presence of subdivision $(9,10)$. There is high subpopulation differentiation if $S_{n n}$ is close to 1 , whereas random exchange exists if $\mathrm{S}_{\mathrm{nn}} \leq 0.05$ (14).

Construction of standard curves for $\boldsymbol{\beta}$-actin and a GVCV fragment. A primer set, Actin 1 (5'-TCCATTGTCCACAGG AAGTGC- $3^{\prime}$ ) and Actin 2 (5'-CCCCACCTCAACACATCTCC$3^{\prime}$ ), was designed to amplify a 138 -bp grapevine $\beta$-actin gene by PCR, which was cloned into the vector pCR8/GW/TOPO. The resultant recombinant plasmid was used for making a standard curve for the $\beta$-actin gene. A previously constructed recombinant plasmid containing a GVCV-specific fragment of 2,580 bp was used for making a standard curve for GVCV. The primers for a quantitative (q)PCR assay of GVCV copy numbers GVCV4142F and GVCV4387R generated a 246-bp fragment. The copy number for the plasmid DNAs was calculated by the equation DNA copy number $=\left[\right.$ amount of DNA $\left.(\mathrm{ng}) \times 6.022 \times 10^{23}\right] /[$ length of DNA (bp) $\times 1 \times 10^{9} \times 650$ ] (5). Plasmid DNA was diluted to make a series of 10 -fold solutions containing $10^{1}$ to $10^{8}$ copies $/ \mu$ of $\mathrm{H}_{2} \mathrm{O}$.

Thermal cycling parameters for amplifying both the GVCV fragment and the $\beta$-actin gene in $\mathrm{qPCR}$ were $95^{\circ} \mathrm{C}$ for $10 \mathrm{~min}$, followed by 60 cycles of $95^{\circ} \mathrm{C}$ for $30 \mathrm{~s}, 59^{\circ} \mathrm{C}$ for $40 \mathrm{~s}$, and $72^{\circ} \mathrm{C}$ for $30 \mathrm{~s}$. The threshold cycle $(\mathrm{Ct})$ value and efficiency were acquired from the Mx3005P QPCR program (Stratagene, Santa Clara, CA) and plotted against the log of the copy number of DNA in each solution. The linear regression of $\mathrm{Ct}$ value of each dilution over the $\log _{10}$ transformation of DNA copy number was calculated to construct a standard curve for $\beta$-actin $\left(R^{2}=0.9995\right)$ and $\operatorname{GVCV}\left(R^{2}=0.9976\right)$.

Relative quantity of GVCV in grapevine tissues by qPCR. DNA was extracted from young leaves, fully expanded leaves, petioles, and root tips of three individual LBC0903 vines, quantified by NanoDrop 2000 (Thermo Scientific, Waltham, MA), and diluted to $10 \mathrm{ng} / \mu \mathrm{l}$. The reactions for qPCR were set up by including $10 \mathrm{ng}$ of DNA using the SYBR Green QPCR Master Mix (Stratagene) and following the manufacturer's recommendations. The thermal cycling program was the same as in the previous section.

The quantity of the $\beta$-actin DNA was calculated for each sample based on the $\beta$-actin gene standard curve, as previously described (24). Similarly, the quantity of GVCV DNA was calculated for each sample based on the GVCV standard curve. The quantity of GVCV was normalized for the quantity of the $\beta$-actin gene in each sample.

\section{RESULTS}

An RFLP assay indicates that GVCV populations are heterogeneous. In a previous study, we collected samples from a vineyard in Missouri and used the primer set GVCV-F1 and GVCV-R1 in PCR to assay them for the presence of GVCV (34). The samples LBC0902, LBC0903, LBC1001, and LBC1003 tested positive, because the PCR assay yielded a product of 530 bp in each sample. To verify the results, we designed another set of primers based on the GVCV reference genome isolated from the grapevine sample LBC0903. Interestingly, GVCV was not detected in sample LBC1001 using the second set of primers (data not shown), which indicated that GVCV sequence variants might be present within a single vineyard. Consequently, we conducted a more thorough analysis of the GVCV population based on RFLPs present in amplified GVCV sequences.

We selected three samples from Missouri (LBC0902, LBC0903, and LBC1003), four samples from Illinois (ILV1001, ILV1002, ILV1003, and ILV1004), and four samples from Indiana (IDV1002, IDV1003, IDV1004, and IDV1005). We designed a primer set of GVCV3163F and GVCV5880R to amplify a DNA fragment of 2,718 bp covering nucleotides 3,163 to 5,880 of the GVCV genome. Based on restriction site analysis of the GVCV reference genome sequence LBC0903 (GenBank accession number JF301669), one restriction site for PstI and ApaI and two restriction sites for EcoRV were predicted within the amplified DNA fragment. As expected, the DNA fragment of the GVCV type isolate in the LBC0903 sample yielded two fragments of 2,092 and 626 bp upon digestion by Pst $\mathrm{I}$; three fragments of 2,052, 543, and 123 bp by EcoRV; and two fragments of 1,032 and 1,686 bp by ApaI (Fig. 1). The digestion of DNA fragments in other samples with the same enzymes, however, generated distinctly different RFLP patterns (Fig. 1), indicating that genetically diverse GVCV populations exist in the vineyards of the three states.

GVCV sequence variants do not cluster by state or grape variety. Distinct RFLP patterns are a result of nucleotide variations within the recognition sites of the three selected restriction enzymes. To further assess the genetic diversity of GVCV variants at the nucleotide sequence level, we sequenced two separate regions in ORF3 of the GVCV genome and performed a phylogenetic analysis. DNA was isolated from 13 separate plants (Table 1), and a 2,580-bp DNA fragment within the ORF3 was amplified from each DNA preparation; three individual clones for each DNA isolate were chosen for sequence analysis. Within the 
2,580-bp DNA GVCV fragment, we selected ZF and RT regions for the phylogenetic analysis, because these sequences form distinct domains within the coat protein and polymerase genes, respectively, and also are used as criteria for differentiating virus species in the genus Badnavirus (11). The ZF region of $540 \mathrm{nt}$ included the 51-nt ZF core sequence plus 489-nt adjacent sequences. The RT region of $570 \mathrm{nt}$ included a 357-nt sequence encoding part of the reverse transcriptase plus 213 nt of downstream sequences. In total, $39 \mathrm{ZF}$ and RT regions were cloned and the nucleotide sequence determined. The overall mean nucleotide diversity in the $\mathrm{ZF}$ region was $0.022 \pm 0.002$ among sequences within an isolate and $0.034 \pm 0.004$ among sequences between isolates. For the RT region, the overall mean nucleotide diversity was $0.019 \pm 0.002$ within an isolate and $0.033 \pm 0.004$ between isolates, respectively. In both regions, nucleotide diversity was lower within an isolate than between isolates, suggesting that differences between isolates were larger than differences among sequence variants within each isolate.

The phylogenetic tree based on the sequences of the $\mathrm{ZF}$ region showed that 16 sequence variants of GVCV were clustered into a large subgroup (Fig. 2A, subgroup I). Similarly, 15 sequence variants could be clustered into a large subgroup upon phylogenetic analysis of the RT sequences (Fig. 2B, subgroup I). Fourteen of the sequence variants were shared between the ZF subgroup I and RT subgroup I (Fig. 2), indicating that these two genomic regions generated similar phylogenetic relationships. The remaining sequence variants in both trees could only be clustered into small clades. Subgroup I for both ZF and RT contained isolates from different grape varieties that were collected from three states. Therefore, no clear separation of GVCV sequence variants was observed according to the geographic location of vineyards and the type of grape variety.

Purifying selection pressure is imposed on the $\mathrm{ZF}$ and RT region of GVCV. Datamonkey software was used to estimate selection pressure on the 180 codons of the ZF region and 190 codons of the RT region. The normalized $\mathrm{d} N-\mathrm{d} S$ value was 0.0551 for the ZF region and 0.0755 for RT region, and $18.90 \%$ codons within the ZF and $13.20 \%$ codons within the RT were under negative selection pressure (Table 2). The results indicate that a slightly stronger selection pressure is acting on the $\mathrm{ZF}$ region than the RT region. The remaining codons were under neutral selection pressure. No codon was found to be under positive selection pressure. These analyses indicated that the selected codons in the $\mathrm{ZF}$ and $\mathrm{RT}$ regions of GVCV are subjected to purifying selection, with a slightly higher pressure on the $\mathrm{ZF}$ than the RT region, implying that there are constraints on nucleotide changes in the $\mathrm{RT}$ and $\mathrm{ZF}$ domains to retain their functionality.

Population genetic analysis suggests differentiation of GVCV. We calculated $\mathrm{F}_{\mathrm{ST}}$ and $\mathrm{S}_{\mathrm{nn}}$ values among GVCV sequence variants using Wright and Hudson's statistics $(9,10,32)$. The higher the $\mathrm{F}_{\mathrm{ST}}$ and $S_{n n}$ values are, the more divergent the two populations $(14,32)$. Pairwise comparisons of both ZF and RT regions found that the $F_{S T}$ values were $>0.05$, except for the $F_{S T}$ of 0.03395 between Missouri and Illinois (Table 3), and the corresponding $S_{n n}$ values also were high, suggesting the existence of genetic differentiation among GVCV populations in the three states. Comparison of both ZF and RT regions of GVCV between two grape varieties indicated that $\mathrm{F}_{\mathrm{ST}}$ values were significantly higher in the comparison of 'Cabernet Sauvignon' with 'Chardonnay', suggesting that the genetic composition of GVCV population in Cabernet Sauvignon is different from GVCV populations in Chardonnay (Table 4). The RT region also differs significantly between Cabernet Sauvignon and Chardonnay (Table 4).

Chambourcin is resistant to GVCV. A previous investigation found that grape varieties of $V$. vinifera as well as hybrid grape Chardonel and Vidal Blanc were susceptible to GVCV (34). Hybrid grape Chambourcin, Cayuga White, and Traminette also are widely grown in the Midwest region. To evaluate the susceptibility of these three hybrids to GVCV, LBC0903 was chip-bud
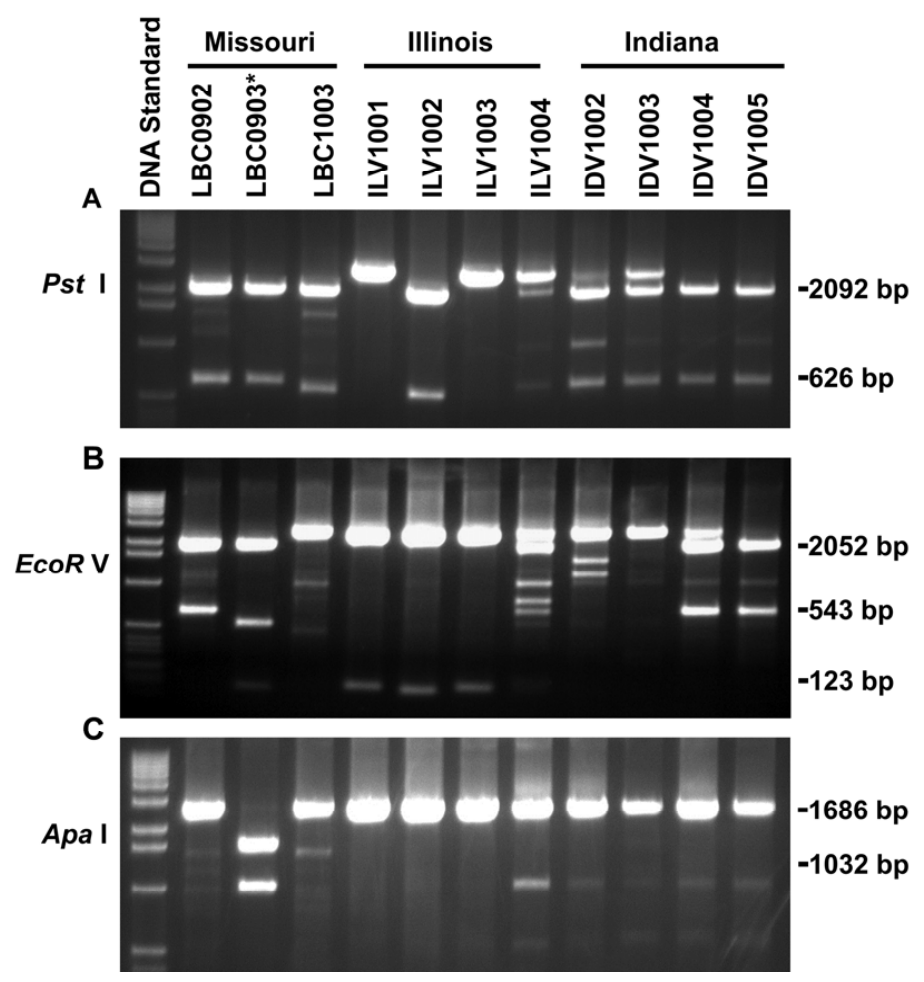

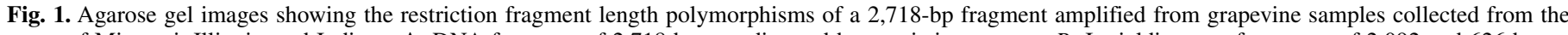

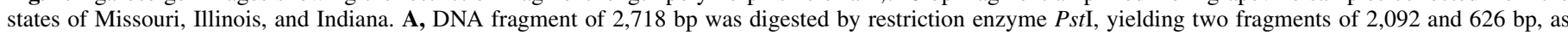

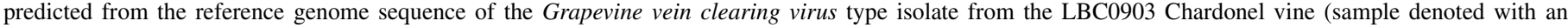

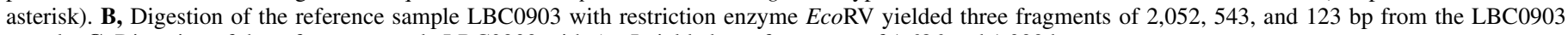
sample. C, Digestion of the reference sample LBC0903 with ApaI yielded two fragments of 1,686 and 1,032 bp. 
grafted onto each cultivar as well as Vidal Blanc, which previously was shown to be susceptible and, thus, used as a control. One year after grafting, the chip-bud-grafted union on Vidal Blanc, Chambourcin, and Cayuga White had healed whereas the graft union on Traminette had not healed; therefore, this hybrid was excluded from further analysis in this experiment. We extracted DNA from leaves of Vidal Blanc, Chambourcin, and Cayuga White and performed the PCR to detect GVCV. GVCV was detected in Vidal Blanc and Cayuga White but not in Chambourcin (Fig. 3), indicating that Vidal Blanc and Cayuga white were susceptible to GVCV and that Chambourcin might be resistant.

In a second experiment to evaluate the susceptibility of Chambourcin to GVCV, hardwood buds of the LBC0903 vines were grafted onto two more Chambourcin vines and also onto a Chardonel vine, previously shown to be susceptible to GVCV (34). The plants were maintained in the greenhouse over the winter. In the spring, the new shoots that emerged from the LBC0903 scion bud as well as from the Chambourcin and Chardonel shoots were tested by PCR for the presence of GVCV. Although GVCV was consistently detected in LBC0903 scion buds and in the grafted Chardonel shoot, it could not be detected in the grafted Chambourcin shoot (data not shown).

In the third experiment, we grafted young shoots of LBC0903 onto the three-node green cuttings of Chambourcin and Traminette. Young leaves of the LBC0903-grafted Traminette vine showed translucent vein-clearing and the shoots were stunted, symptoms typical of GVCV infection (Fig. 4A), whereas the LBC0903-grafted Chambourcin did not show visible symptoms (Fig. 4B). To determine whether GVCV had been transmitted to either Chambourcin or Traminette, total DNA was isolated from both the scion (LBC0903) and shoot tissues (Traminette or Chambourcin) and subjected to a PCR assay for detection of GVCV. The results show that GVCV was present in LBC0903 scion branches and also in the grafted Traminette shoot but not in the grafted Chambourcin shoot (Fig. 4C). In each of these three ex-

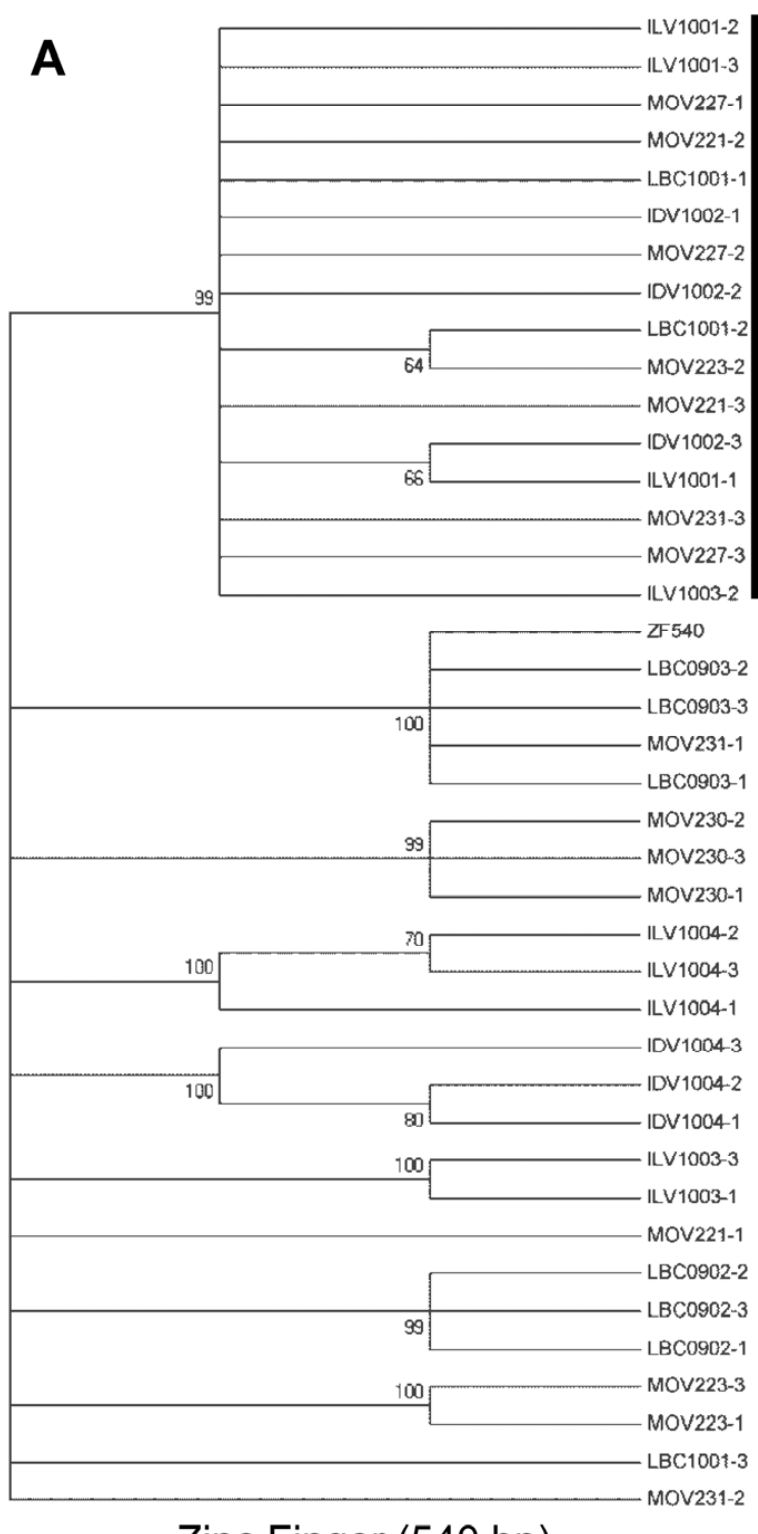

Zinc Finger (540 bp)

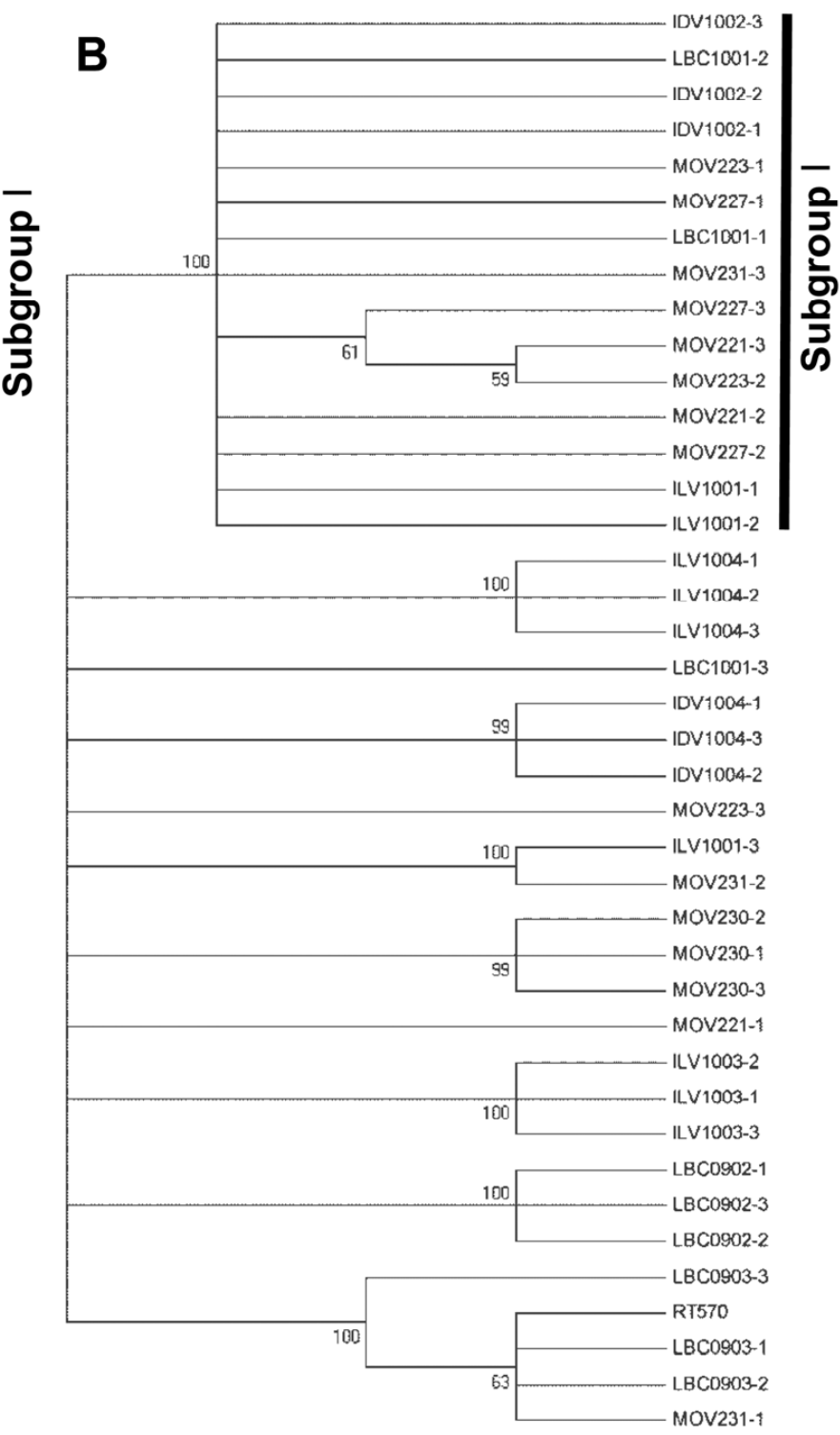

Reverse Transcriptase (570 bp)

Fig. 2. Phylogenetic analysis of Grapevine vein clearing virus (GVCV) isolates. A, Phylogenetic analysis of predicted zinc finger (ZF) regions of 39 sequence variants based on the nucleotide sequences and $\mathbf{B}$, phylogenetic analysis of predicted reverse-transcriptase (RT) regions of 39 sequence variants. Unrooted trees were generated by maximum likelihood method using the best models with bootstrap replicates at 1,000 in the MEGA5 software. Branches reproduced in $<50 \%$ of bootstrap replicates were collapsed. ZF540 and RT570 were reference sequences of ZF and RT regions of the GVCV type isolate (GenBank accession number JF301669). 
periments, we successfully transmitted GVCV from LBC0903 to susceptible grape hybrids but we were unable to transmit GVCV to Chambourcin. Consequently, we conclude that Chambourcin is able to resist infection by GVCV.

Susceptible varieties do not exert strong selection pressure on the codons of GVCV. To investigate whether a susceptible grape variety imposes selection pressure on the structure of GVCV populations, we sequenced the 540-nt ZF and 570-nt RT regions of three GVCV sequence variants isolated from the Vidal Blanc, Cayuga White, and Traminette vines that had been grafted with LBC0903. Collectively, the sequences of the $\mathrm{ZF}$ region were 99.3\% identical to the GVCV type isolate in LBC0903, whereas the RT regions were $99.6 \%$ identical to $\mathrm{LBC} 0903$. For the ZF region, four nucleotide changes were found, and two of them caused amino acid changes. For the RT region, there were also four nucleotide changes but only one led to an amino acid change (Fig. 5). Overall, seven nucleotide changes were found in the sequenced $\mathrm{ZF}$ and RT regions of GVCV isolated from Traminette and only one was found in the GVCV sequences from Cayuga White. The sequences of the two regions of GVCV from Vidal Blanc were identical to the corresponding region of the GVCV type isolate.

Copy number of GVCV is the lowest in root tip. To investigate the distribution of GVCV in young leaves, fully expanded leaves, petioles, and root tips in the LBC0903 vine, we constructed a standard curve for a grapevine $\beta$-actin gene $\left(R^{2}=\right.$

TABLE 2. Estimated selection pressure for the zinc-finger (ZF) and reverse-transcriptase (RT) regions of Grapevine vein clearing virus

\begin{tabular}{|c|c|c|c|c|c|c|c|c|}
\hline \multirow[b]{2}{*}{ Region $^{\mathrm{a}}$} & \multicolumn{2}{|c|}{ Normalized $\mathrm{d} N-\mathrm{d} S^{\mathrm{b}}$} & \multicolumn{2}{|c|}{ Positive selection $^{\mathrm{c}}$} & \multicolumn{2}{|c|}{ Negative selection } & \multicolumn{2}{|c|}{ Neutral selection } \\
\hline & $\log (\mathrm{L})$ & Mean & Number & Percent & Number & Percent & Number & Percent \\
\hline $\mathrm{ZF}$ & -1745.11 & 0.0551 & 0 & 0 & 34 & 18.90 & 146 & 81.10 \\
\hline RT & -1722.39 & 0.0755 & 0 & 0 & 25 & 13.20 & 165 & 86.80 \\
\hline
\end{tabular}

a Data were obtained by the analysis of 180 codons for ZF region and 190 codons for RT region.

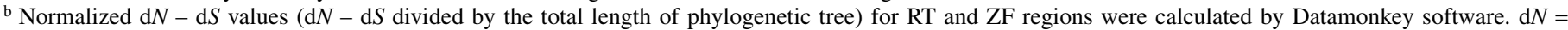
nonsynonymous substitutions per nonsynonymous site and $\mathrm{d} S=$ synonymous substitutions per synonymous site. $\mathrm{d} N-\mathrm{d} S<1$ means negative or purifying selection pressure, $\mathrm{d} N-\mathrm{d} S>1$ positive or diversifying selection pressure, and $\mathrm{d} N-\mathrm{d} S=1$ means neutral selection pressure.

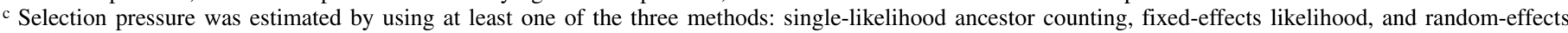
likelihood.

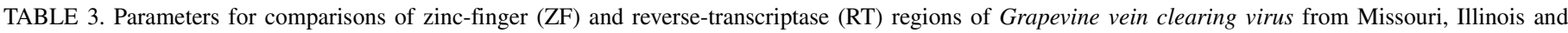
Indiana $^{\mathrm{a}}$

\begin{tabular}{|c|c|c|c|c|c|}
\hline Genomic region and comparison $^{\mathrm{b}}$ & $\mathrm{K}_{\mathrm{ST}} *$ & $P$ value & $\mathrm{S}_{\mathrm{nn}}$ & $P$ value & $\mathrm{F}_{\mathrm{ST}}$ \\
\hline \multicolumn{6}{|l|}{ ZF540 } \\
\hline Missouri vs. Illinois & 0.01804 & $0.0860 \mathrm{~ns}$ & 0.82973 & $0.0000 * * *$ & 0.03395 \\
\hline Missouri vs. Indiana & 0.02310 & $0.0780 \mathrm{~ns}$ & 0.86111 & $0.0040 * *$ & 0.12630 \\
\hline Illinois vs. Indiana & 0.04843 & $0.1310 \mathrm{~ns}$ & 0.68333 & $0.0950 \mathrm{~ns}$ & 0.12155 \\
\hline \multicolumn{6}{|l|}{ RT570 } \\
\hline Missouri vs. Illinois & 0.03810 & $0.0170^{*}$ & 0.76263 & $0.0180 *$ & 0.12648 \\
\hline Missouri vs. Indiana & 0.01813 & $0.1080 \mathrm{~ns}$ & 0.71667 & $0.2670 \mathrm{~ns}$ & 0.10920 \\
\hline Illinois vs. Indiana & 0.08864 & $0.0360 *$ & 0.75000 & $0.0400 *$ & 0.20369 \\
\hline
\end{tabular}

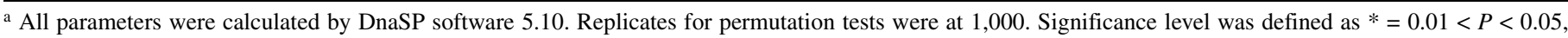

$* *=0.001<P<0.01, * * *=P<0.001$, and ns = not significant.

b Number of sequence variants used in the analysis: 24 from Missouri; 9 from Illinois; 6 from Indiana.

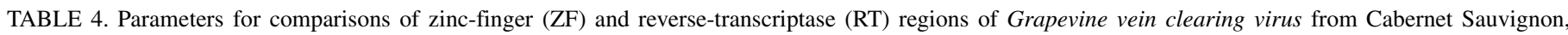
Chardonnay, Chardonel, Cabernet Franc, and Riesling ${ }^{a}$

\begin{tabular}{|c|c|c|c|c|c|}
\hline Genomic region and comparison $^{\mathrm{b}}$ & $\mathrm{K}_{\mathrm{ST}} *$ & $P$ value & $\mathrm{S}_{\mathrm{nn}}$ & $P$ value & $\mathrm{F}_{\mathrm{ST}}$ \\
\hline \multicolumn{6}{|l|}{ ZF540 } \\
\hline Cabernet Sauvignon vs. Chardonnay & 0.12691 & $0.0130 *$ & 0.76190 & $0.0070 * *$ & 0.21069 \\
\hline Cabernet Sauvignon vs. Chardonel & 0.02956 & $0.0530 \mathrm{~ns}$ & 0.67725 & $0.0640 \mathrm{~ns}$ & 0.08754 \\
\hline Cabernet Sauvignon vs. Cabernet Franc & -0.06883 & $0.8010 \mathrm{~ns}$ & 0.63889 & $0.3890 \mathrm{~ns}$ & 0.13663 \\
\hline Cabernet Sauvignon vs. Riesling & 0.23382 & $0.0050 * *$ & 1.00000 & $0.0050 * *$ & 0.68371 \\
\hline Chardonnay vs. Chardonel & 0.03194 & $0.0510 \mathrm{~ns}$ & 0.77778 & $0.0300 *$ & 0.06069 \\
\hline Chardonnay vs. Cabernet Franc & 0.12454 & $0.0480 *$ & 0.71296 & $0.0840 \mathrm{~ns}$ & 0.46682 \\
\hline Chardonnay vs. Riesling & 0.20067 & $0.0080 * *$ & 1.00000 & $0.0110 *$ & 0.58770 \\
\hline Chardonel vs. Cabernet Franc & -0.00867 & $0.5740 \mathrm{~ns}$ & 0.74762 & $0.4620 \mathrm{~ns}$ & 0.31572 \\
\hline Chardonel vs. Riesling & 0.06773 & $0.0030 * *$ & 0.97619 & $0.0040 * *$ & 0.54769 \\
\hline Cabernet Franc vs. Riesling & 0.67455 & $0.0990 \mathrm{~ns}$ & 1.00000 & $0.0990 \mathrm{~ns}$ & 0.95745 \\
\hline \multicolumn{6}{|l|}{ RT570 } \\
\hline Cabernet Sauvignon vs. Chardonnay & 0.13196 & $0.0030 * *$ & 0.85000 & $0.0030 * *$ & 0.33195 \\
\hline Cabernet Sauvignon vs. Chardonel & 0.05628 & $0.0130 *$ & 0.71605 & $0.0350 *$ & 0.22216 \\
\hline Cabernet Sauvignon vs. Cabernet Franc & -0.08468 & $0.9140 \mathrm{~ns}$ & 0.43333 & $0.9430 \mathrm{~ns}$ & 0.06346 \\
\hline Cabernet Sauvignon vs. Riesling & 0.24300 & $0.0030 * *$ & 0.83333 & $0.0070 * *$ & 0.74079 \\
\hline Chardonnay vs. Chardonel & 0.02043 & $0.0910 \mathrm{~ns}$ & 0.75000 & $0.0810 \mathrm{~ns}$ & 0.09049 \\
\hline Chardonnay vs. Cabernet Franc & 0.13431 & $0.1070 \mathrm{~ns}$ & 0.88889 & $0.0130 *$ & 0.54793 \\
\hline Chardonnay vs. Riesling & 0.14430 & $0.0040 * *$ & 0.88889 & $0.0100 *$ & 0.52982 \\
\hline Chardonel vs. Cabernet Franc & 0.01683 & $0.1720 \mathrm{~ns}$ & 0.80000 & $0.2000 \mathrm{~ns}$ & 0.43213 \\
\hline Chardonel vs. Riesling & 0.05179 & $0.0060 * *$ & 1.00000 & $0.0050 * *$ & 0.48972 \\
\hline Cabernet Franc vs. Riesling & 0.81172 & $0.0970 \mathrm{~ns}$ & 1.00000 & $0.0970 \mathrm{~ns}$ & 0.97674 \\
\hline
\end{tabular}

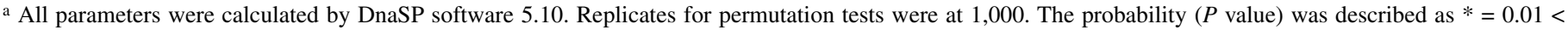
$P<0.05, * *=0.001<P<0.01, * * *=P<0.001$, and $\mathrm{ns}=$ not significant.

b Number of sequence variants in the analysis: 9 in Cabernet Sauvignon, 6 in Chardonnay, 18 in Chardonel, 3 in Cabernet Franc, and 3 in Riesling. 
$0.9995)$ and $\operatorname{GVCV}\left(R^{2}=0.9976\right)$. The amplification efficiency was $102.2 \%$ for GVCV and $114.4 \%$ for the $\beta$-actin gene. We calculated the copy number of the $\beta$-actin gene and GVCV in each tissue for three individual LBC0903 vines based on the standard curve. The copy number of GVCV was $\log _{10}$ transformed and normalized by the $\log _{10}$-transformed copy number of the $\beta$-actin gene. We found that GVCV had an average of 4.6 copies per actin in a young leaf, 3.7 in a fully expanded leaf, 14.4 in a petiole, and 0.5 in a root tip. Analysis of variance of the $\log _{10^{-}}$ transformed copy number indicated that the quantity of GVCV in the root tip was significantly different from that of GVCV in the other three tissues $(P=0.05)$ (Fig. 6).

\section{DISCUSSION}

A new virus disease has recently emerged in grapevines from Midwest vineyards in which the diagnostic symptom is translucent vein clearing along the main veins of fully expanded young leaves. A badnavirus, GVCV, has consistently been associated with symptomatic vines in six grape varieties from vineyards in Missouri, Illinois, and Indiana (34). In the present study, an RFLP analysis of a defined genomic region of GVCV revealed the first glimpse of the diversity of GVCV isolates from commercial vineyards in the three states (Fig. 1). To further characterize the population structure of GVCV, we amplified RT and ZF regions from 13 symptomatic vines, with eight collected from Missouri, three from Illinois, and two from Indiana. Three GVCV clones were sequenced from the PCR products amplified from each vine, and a nucleotide sequence analysis of the two specific regions verified the existence of genetically diverse GVCV populations. The number of nucleotide changes among the three sequences obtained from one isolate was lower than those between isolates, implying that the sequence variations between isolates are a result of GVCV-originated genetic changes, not of PCR-introduced errors.

The 39 sequence variants were not clearly clustered by geographic location. It is true that the $\mathrm{ZF}$ region of the GVCV variants from Missouri were significantly different from those variants in the other two states (Table 3) but the RT region from the same Missouri isolates was not differentiated from those collected in Illinois and Indiana. One possibility is that a large sample size in Missouri might have skewed the results. In total, 24 GVCV variants were sequenced from Missouri, compared with nine from Illinois and six from Indiana. Furthermore, the phylogenetic analysis was performed on the ZF and RT regions of the GVCV genome rather than the entire genomic sequence; therefore, our analysis is only one snapshot of genomic variation that exists among GVCV isolates. It is possible that the phylogeny might be different if the entire genomes of all 39 isolates were

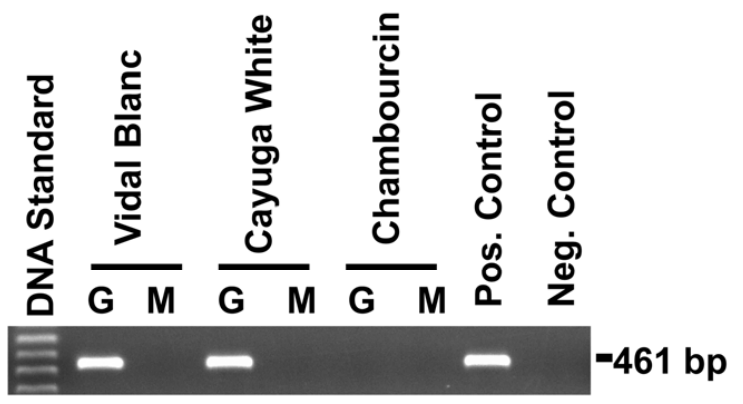

Fig. 3. Agarose gel images showing the presence of Grapevine vein clearing virus (GVCV)-specific DNA fragment. Vidal Blanc, Cayuga White, and Chambourcin vines were grafted with one-node woody chip from the GVCVinfected LBC0903 vine. $G=$ GVCV-grafted vine and $M=$ mock-grafted vine. The positive control polymerase chain reaction (PCR) was run with the LBC0903 DNA template. The negative control PCR contained no DNA template. analyzed. High volumes of vegetative propagation and frequent exchanges of plant germplasm across regions and countries may dilute close associations of a virus species with genotypes or geographical locations. This appears to be the case for most grapevine viruses $(2,3,13,19,30)$, as well as for GVCV. For example, it has been documented that variants of GRSPaV and
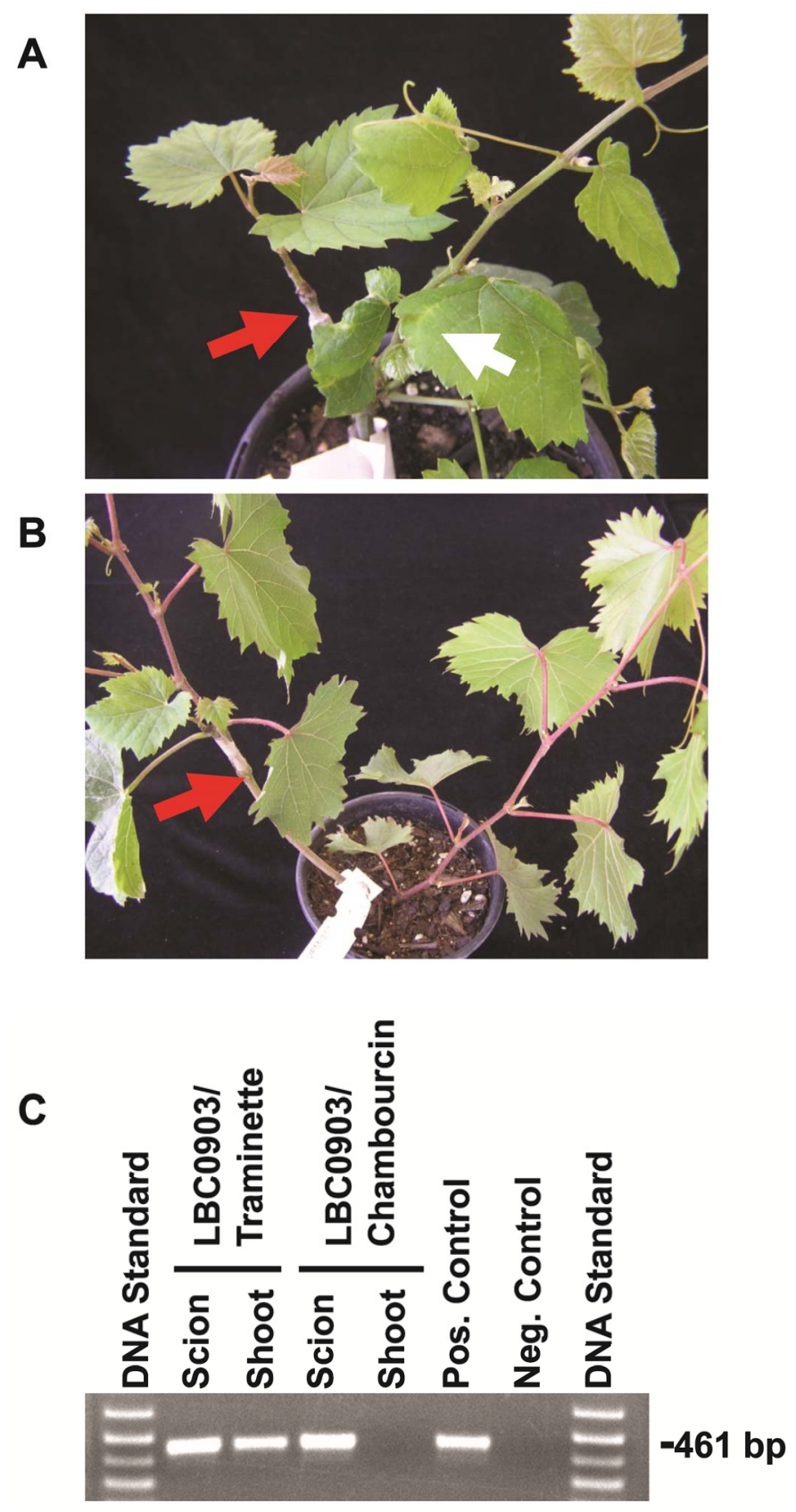

Fig. 4. Development of symptoms on Grapevine vein clearing virus (GVCV)grafted grapevines. A, Appearance of vein-clearing and leaf distortion on Traminette vine after grafting with a green shoot of two nodes of GVCVinfected LBC0903 grapevine. B, Absence of symptoms on GVCV-grafted Chambourcin vine. Photos were taken 50 days post grafting. In both A and B, the red arrow points to the graft union above which the GVCV-infected LBC0903 Chardonel shoot is alive, whereas the white arrow in A indicates the diagnostic symptoms of vein clearing and deformed leaf on the GVCV-grafted Traminette vine. C, Agarose gel image showing the presence of GVCV in LBC0903 scion and grafted Traminette vine but not in grafted Chambourcin vine. The scion was from GVCV-infected LBC0903, whereas the shoot sample was from either Traminette or Chambourcin, as indicated. GVCV was detected by the amplification of a 461-bp fragment using primers GVCV5098F and GVCV5558R in polymerase chain reaction (PCR). The positive-control PCR was run with the LBC0903 template, and the negative control PCR contained no DNA template. 
GLRaV-1, 2, and -3 are not clustered based on the geographical origins $(2,3,13,19,30)$. A lack of clearly defined genetic separation and isolation reinforces the hypothesis that grapevine viruses are transmitted mainly through vegetative propagation and frequent movement of propagated materials across regions.

Plant DNA viruses in the genus Badnavirus are present in nature as genetically divergent populations with many single nucleotide polymorphisms between isolates. Although our results demonstrated the existence of divergent GVCV sequence variants in vineyards, the level of genetic diversity was lower than that for CSSV and BSV. For example, the genetic variation between CSSV isolates is as high as $29.4 \%$ at the whole-genomicsequence level (21), whereas genetic diversity of BSV isolates is so high that six species were proposed to classify BSV isolates (12).

Heterogeneity in a virus population arises as a result of two sources. One source occurs during replication. For plant badnaviruses, the RT and RNase $\mathrm{H}$ are necessary for synthesis of viral genomic DNA from a template consisting of a terminally redundant transcript. The low proofreading capacity of the RT generally produces progeny DNA molecules that accumulate mutated nucleotides throughout the genome. A second source of heterogeneity occurs through positive or negative selection pressure from hosts of different genetic backgrounds. An analysis of the normalized $\mathrm{d} N-\mathrm{d} S$ values indicated that purifying (negative) selection pressure was acting on selected codons of the RT and $\mathrm{ZF}$ regions of the GVCV genome, implying that there are some constraints on evolutionary changes of the nucleotides in these domains to retain their biological functionality. A slightly higher portion of the 180 codons $(18.90 \%)$ in the $\mathrm{ZF}$ region was under purifying selection pressure than the 190 codons in the RT region (Table 2). Similarly, previous results with GRSPaV demonstrated that the coat protein gene was more variable than the helicase coding region (3). Functional constraints have also been found to be imposed on mutation rates in separate regions across the genome of GLRaV-1 (2), GLRaV-2 (13), and Squash vein yellowing virus (31). It is likely that the selection of nucleotides is closely linked with the functionality of the encoded protein.

In addition to examining the population structure of GVCV in multiple grapevine hosts, we also investigated potential sources for GVCV within host tissues. We found that the copy number of GVCV relative to the actin gene was significantly lower in the root tip than in leaf and petiole tissues (Fig. 6), implying that root tips do not support efficient multiplication of GVCV or fewer

\begin{tabular}{|c|c|c|c|c|c|c|}
\hline \multirow[b]{2}{*}{ Cayuga White-1 } & \multicolumn{4}{|c|}{ Zinc Finger Region } & \multicolumn{2}{|c|}{$R T$ region } \\
\hline & GTT & CAA & CAG & TCA & TTC & ATC \\
\hline Cayuga White-2 & $\underline{G} \underline{T} T$ & CAA & CAG & TCA & TTC & ATC \\
\hline Cayuga White-3 & $\overline{\mathrm{GTT}}$ & CAA & CAG & TCA & TTC & ATC \\
\hline Traminette-1 & GTT & CAG & CAG & TCA & TTC & AT $\underline{A}$ \\
\hline Traminette-2 & GTT & $\mathrm{CA} \bar{A}$ & CGGG & TCG & $\underline{\mathbf{c}}$ TC & AT $\overline{\bar{A}}$ \\
\hline Traminette-3 & GTT & CAA & $\overline{C A G}$ & TCA & TTC & AT $\underline{A}$ \\
\hline Vidal Blanc-1 & GTT & CAA & CAG & TCA & TTC & AT $\bar{C}$ \\
\hline Vidal Blanc-2 & GTT & CAA & CAG & TCA & TTC & ATC \\
\hline Vidal Blanc-3 & GTT & CAA & CAG & TCA & TTC & ATC \\
\hline \multirow[t]{3}{*}{ LBC0903 } & GTT & CAA & CAG & TCA & TTC & ATC \\
\hline & $\mathrm{Val} \rightarrow \mathrm{Ala}$ & $\mathrm{Gln} \rightarrow \mathrm{Gln}$ & $\mathrm{Gln} \rightarrow \operatorname{Arg}$ & Ser $\rightarrow$ Ser & Phe $\rightarrow$ Leu & $\|e \rightarrow\| e$ \\
\hline & $4478 \mathrm{nt}$ & $4515 \mathrm{nt}$ & $4565 \mathrm{nt}$ & $4686 \mathrm{nt}$ & $6082 \mathrm{nt}$ & $6132 \mathrm{nt}$ \\
\hline
\end{tabular}

Fig. 5. Changes of nucleotides in the sequenced zinc-finger and reversetranscriptase (RT) regions of Grapevine vein clearing virus (GVCV) from the GVCV type isolate LBC0903-grafted Cayuga White, Traminette, and Vidal Blanc. Eight nucleotide changes were found in both regions and three of them caused amino changes. Overall, seven nucleotides (in bold and underlined) were changed in the two regions of GCVC isolated from grafted Traminette and one was in both regions of GVCV from grafted Cayuga White. No nucleotide changes were found in the regions of GVCV from grafted Vidal Blanc. cells are infected with GVCV than in leaf and petiole tissues. GVCV accumulates abundantly in the petiole, which is consistent with the high concentration of most grapevine viruses in phloem tissues (26). Therefore for sensitive detection, the petiole is the best tissue for sampling. Finally, we examined the capacity of GVCV to infect different grape hybrids. Little is known about host resistance to grapevine viruses. Experimental grafting of GVCV-infected buds onto Chambourcin, Vidal Blanc, Cayuga White, and Traminette showed that GVCV could not be detected in Chambourcin (Figs. 3 and 4), suggesting that Chambourcin is resistant to GVCV. It is not clear whether this resistance is a result of barrier to transmission of GVCV via the graft union or inhibition to the replication of GVCV in the Chambourcin cells. The parentage of Chambourcin is unknown, although Seyve'Villard12-417' and 'Seibel 7053' are listed as two candidate parents on the national grape registry (http://ngr.ucdavis.edu/). Why Chambourcin shows resistance to GVCV is an intriguing question that deserves a more detailed genetic analysis, because the genetic basis of host resistance to grapevine viruses is critical for breeding virus-resistant grape cultivars. Furthermore, it remains to be answered whether susceptible grapevine varieties select for and shape the GVCV population in a vineyard.

The results from this study provide knowledge that has several practical applications. Sequences of the two regions of $39 \mathrm{GVCV}$ sequence variants will allow the identification of conserved nucleotide sequences for designing primers. These conserved primers can be used to reliably detect GVCV isolates that are distributed in commercial vineyards. Both leaf and petiole tissues can be used for reproducible detection of GVCV. The hybrid grape Chambourcin could be valuable in areas where GVCV is endemic and for breeding GVCV-resistant grape varieties. The diversity of GVCV creates challenges for tracking the original sources of the virus and developing resistant grape varieties.
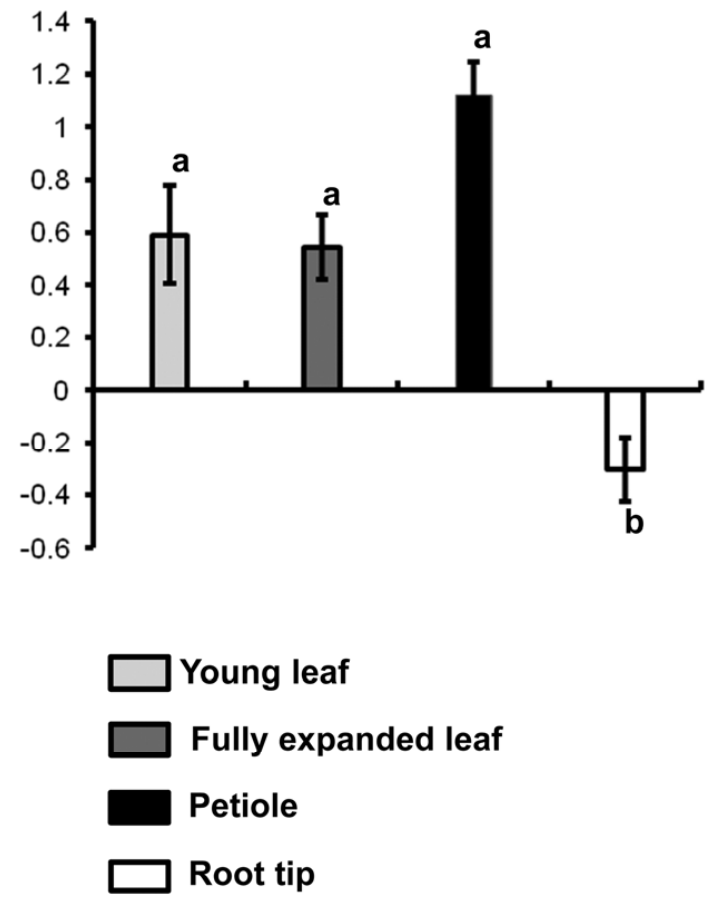

Fig. 6. Histogram of normalized quantity of Grapevine vein clearing virus (GVCV) in young leaf, fully expanded leaf, petiole, and root tip of the LBC0903 vine. Y-axis is the $\log _{10}$-transformed copy number of GVCV after it was normalized by the copy number of $\beta$-actin gene in each tissue. Data were collected from four types of tissues of three individual LBC0903 vines. Vertical bars indicate the standard error. Bars with the same letter ( $a$ or b) are not significantly different based on analysis of variance in the NCSS 2007 program (NCSS Inc., Kaysville, UT). The mean and standard error were calculated using Minitab15 (Minitab Inc., State College, PA). 


\section{ACKNOWLEDGMENTS}

This research was supported by a grant (United States Department of Agriculture [USDA]-NIFA 2010-38901-20939) from the USDA and a USDA-National Clean Plant Network grant. We thank Herman Scholthof for critical reviewing of the manuscript. We are grateful to John Avery for performing chip bud-grafting.

\section{LITERATURE CITED}

1. Acosta-Leal, R., Duffy, S., Xiong, Z., Hammond, R., and Elena, S. F. 2011. Advances in plant virus evolution: Translating evolutionary insights into better disease management. Phytopathology 101:1136-1148.

2. Alabi, O. J., Al Rwahnih, M., Karthikeyan, G., Poojari, S., Fuchs, M., Rowhani, A., and Naidu, R. A. 2011. Grapevine leafroll-associated virus 1 occurs as genetically diverse populations. Phytopathology 101:14461456.

3. Alabi, O. J., Martin, R. R., and Naidu, R. A. 2010. Sequence diversity, population genetics and potential recombination events in Grapevine rupestris stem pitting-associated virus in Pacific North-West vineyards. J. Gen. Virol. 91:265-276.

4. Esteves, F., Teixeira Santos, M., Eiras-Dias, J., and Fonseca, F. 2012. Occurrence of Grapevine leafroll-associated virus 5 in Portugal: genetic variability and population structure in field-grown grapevines. Arch. Virol. 157:1747-1765.

5. Gadiou, S., Ripl, J., Janourova, B., Jarosova, J., and Kundu, J. K. 2012. Real-time PCR assay for the discrimination and quantification of wheat and barley strains of Wheat dwarf virus. Virus Genes 44:349-355.

6. Geering, A., McMichael, L. A., Dietzgen, R. G., and Thomas, J. E. 2000. Genetic diversity among Banana streak virus isolates from Australia. Phytopathology 90:921-927.

7. Harper, G., Hart, D., Moult, S., and Hull, R. 2004. Banana streak virus is very diverse in Uganda. Virus Res. 100:51-56.

8. Harper, G., Hart, D., Moult, S., Hull, R., Geering, A., and Thomas, J. 2005. The diversity of Banana streak virus isolates in Uganda. Arch. Virol. 150:2407-2420.

9. Hudson, R. R. 2000. A new statistic for detecting genetic differentiation. Genetics 155:2011-2014.

10. Hudson, R. R., Boos, D. D., and Kaplan, N. L. 1992. A statistical test for detecting geographic subdivision. Mol. Biol. Evol. 9:138-151.

11. Hull, R., Geering, A., Harper, G., Lockhart, B. E., and Schoelz, J. E. 2005. Genus Badnavirus. Pages 392-396 in: Virus Taxonomy: 8th Report of the International Committee for Taxonomy of Viruses. C. M. Fauquet, M. A. Mayo, J. Maniloff, U. Desselberger, and L. A. Ball, eds. Elsevier Academic Press, San Diego, CA.

12. James, A. P., Geijskes, R. J., Dale, J. L., and Harding, R. M. 2011. Molecular characterisation of six badnavirus species associated with leaf streak disease of banana in East Africa. Ann. Appl. Biol. 158:346-353.

13. Jarugula, S., Alabi, O. J., Martin, R. R., and Naidu, R. A. 2010. Genetic variability of natural populations of Grapevine leafroll-associated virus 2 in Pacific Northwest vineyards. Phytopathology 100:698-707.

14. Kaye, A. C., Moyer, J. W., Parks, E. J., Carbone, I., and Cubeta, M. A. 2011. Population genetic analysis of Tomato spotted wilt virus on peanut in North Carolina and Virginia. Phytopathology 101:147-153.

15. Kosakovsky Pond, S. L., and Frost, S. D. W. 2005. Datamonkey: rapid detection of selective pressure on individual sites of codon alignments. Bioinformatics 21:2531-2533.

16. Krenz, B. R., Thompson, J. R., Fuchs, M., and Perry, K. L. 2012. Complete genome sequence of a new circular DNA virus from grapevine. J. Virol. 86:7715.
17. Martelli, G. P. 2012. Grapevine virology highlights: 2010-2012. Pages 1331 in: Proc. 17th Congr. Int. Counc. Study Virus Virus-like Dis. Grapevine. ICVG, Davis, CA.

18. Martelli, G. P., and Boudon-Padieu, E. 2006. Directory of infectious diseases of grapevines and viruses and virus-like diseases of the grapevine: bibliographic report of 1998-2004. In: Opt. Mediterr. Ser. B: N.55. CIHEAM, Bari, Italy.

19. Meng, B., Rebelo, A. R., and Fisher, H. 2006. Genetic diversity analyses of grapevine Rupestris stem pitting-associated virus reveal distinct population structures in scion versus rootstock. J. Gen. Virol. 87:17251733.

20. Muller, E., Dupuy, V., Blondin, L., Bauffe, F., Daugrois, J.-H., Nathalie, L., and Iskra-Caruana, M.-L. 2011. High molecular variability of sugarcane bacilliform viruses in Guadeloupe implying the existence of at least three new species. Virus Res. 160:414-419.

21. Muller, E., and Sackey, S. 2005. Molecular variability analysis of five new complete Cacao swollen shoot virus genomic sequences. Arch Virol. 150:53-66.

22. Nolasco, G., Santos, C., Petrovic, N., Teixeira Santos, M., Cortez, I., Fonseca, F., Boben, J., Nazaré Pereira, A. M., and Sequeira, O. 2006. Rupestris stem pitting associated virus isolates are composed by mixtures of genomic variants which share a highly conserved coat protein. Arch. Virol. 151:83-96.

23. Oliver, J. E., Vigne, E., and Fuchs, M. 2010. Genetic structure and molecular variability of Grapevine fanleaf virus populations. Virus Res. 152:30-40.

24. Péréfarres, F., Hoareau, M., Chiroleu, F., Reynaud, B., Dintinger, J., and Lett, J. 2011. A novel synthetic quantification standard including virus and internal report targets: application for the detection and quantification of emerging begomoviruses on tomato. Virol. J. 8:839.

25. Qiu, W. P., Avery, J. D., and Lunden, S. 2007. Characterization of a severe virus-like disease in Chardonnay grapevines in Missouri. Plant Health Progress. Online publication. doi:10.1094/PHP-2007-111901-BR

26. Rowhani, A., Uyemoto, J. K., Golino, D. A., and Martelli, G. P. 2005. Pathogen testing and certification of Vitis and Prunus species. Annu. Rev. Phytopathol. 43:261-278.

27. Sokhandan-Bashir, N., and Melcher, U. 2012. Population genetic analysis of Grapevine fanleaf virus. Arch. Virol. 157:1-11.

28. Tamura, K., Peterson, D., Peterson, N., Stecher, G., Nei, M., and Kumar, S. 2011. MEGA5: molecular evolutionary genetics analysis (MEGA) using maximum likelihood, evolutionary distance, and maximum parsimony methods. Mol. Biol. Evol. 28:2731-2739.

29. Thomas, J. D., Higgins, D. G., and Gibson, T. J. 1994. CLUSTAL W: improving the sensitivity of progressive multiple sequence alignment through sequence weighting, position-specific gap penalties and weight matrix choice. Nucleic Acid Res. 22:4673-4680.

30. Wang, J., Sharma, A. M., Duffy, S., and Almeida, R. P. P. 2011. Genetic diversity in the $3^{\prime}$ terminal 4.7-kb region of Grapevine leafroll-associated virus 3. Phytopathology 101:445-450.

31. Webster, C. G., and Adkins, S. 2012. Low genetic diversity of Squash vein yellowing virus in wild and cultivated cucurbits in the U.S. suggests a recent introduction. Virus Res. 163:520-527.

32. Wright, S. 1951. The genetical structure of population. Ann. Hum. Genet. 15:323-354.

33. Xu, D., Mock, R., Kinard, G., and Li, R. 2011. Molecular analysis of the complete genomic sequences of four isolates of Gooseberry vein banding associated virus. Virus Genes 43:130-137.

34. Zhang, Y., Singh, K., Kaur, R., and Qiu, W. 2011. Association of a novel DNA virus with the grapevine vein-clearing and vine decline syndrome. Phytopathology 9:1081-1090. 